\title{
A Research Agenda for Social Innovation - the emergence of a research field
}

\author{
Jürgen Howaldt, Christoph Kaletka and Antonius \\ Schröder
}

While the concept of innovation has become more and more important for societies to cope with the great societal challenges, technological and economic innovation encounters limitations in resolving them. To this end, Social Innovation has increasingly been attracting attention in recent years. As a novel approach to address complex problems in global health, social care, education, energy, and environmental policies, Social Innovation has been embraced by stakeholders and communities on the local, regional, and even national level (Franz et al. 2012; Moulaert et al. 2013; Nicholls et al. 2015; Howaldt et al. 2018, 2019; Mulgan 2019).

Even though the concept is currently enjoying a great deal of attention, the discussion goes far back in time. As Benoit Godin has pointed out in his manifold publications on the subject, the terms 'social innovation' and 'social innovator' first started appearing more frequently at the beginning of the nineteenth century - and hence long before the technological and economic appropriation of the term 'innovation' (2012; Chapter 1). Semantically, from the outset, they were closely linked to processes of social transformation as specific forms of social change.

At the beginning of the twentieth century, a new meaning emerged: social innovation as the advent or adoption of a new behaviour or a new practice. With the social world composed of such practices, which are individual yet interdependent, they encompass all areas of society, such as gender relations, formal and informal education, management, governance as well as everyday life, established habits and cultural customs. 
Meanwhile, the importance of Social Innovation in successfully addressing social, economic, political and environmental challenges of the twenty-first century has been recognized on a global scale. Due to expanding and entirely new social demands, reinforced by the challenges of globalization, population growth, increasing inequality, social conflicts and - not least - climate change, the need for social measures of all types rockets high. Social innovation has become a ubiquitous concept. We see countless approaches and successful initiatives that illustrate the strengths and potential of social innovations in manifold areas of social integration through education and poverty reduction, in establishing sustainable patterns of consumption, or in coping with demographic change (Howaldt et al. 2018, 2019).

\section{The emergence of a research field}

Since the 1980s, the term Social Innovation has been increasingly used in a number of research fields. These initially include management and organizational research, work and service research, creativity research, as well as research in the field of local and regional development (Moulaert et al. 2005). In addition, there is sustainability research, research on the digitization of the economy and society, and the field of social entrepreneurship and the economic space for Social Innovation (de Bruin and Teasdale 2019; Nicholls and Ziegler 2019) which has become increasingly important (Howaldt and Schwarz 2010; Ayob et al. 2016; Pue et al. 2016). In each of these fields, as well as in many others, research networks and communities have emerged. On the one hand, this research field as a whole is strongly linked to practice, as far as its thematic scope is concerned. The conceptual discussion around the term - if conducted at all - remains largely confined to the respective research communities in these specific fields (Pue et al. 2016, pp. 50-51). In each of these fields are found specific emphases, questions and, aligned with these, different definitions and understandings of Social Innovation (Rüede and Lurtz 2012; Choi and Majumdar 2015).

Many research projects deal with very concrete practical issues in areas such as education, health care or mobility. On the other hand, both Social Innovation Research and practice themselves used to be two relatively fragmented areas with insufficiently connected actors and networks. The multidisciplinary nature of Social Innovation Research offers an important potential for development of new research perspectives that can help to advance towards new responses to societal challenges. At the same time, such new perspectives can 
facilitate new approaches to social innovation practice (Domanski and Kaletka 2017).

Against the background of the increasing importance of the concept and a largely neglected theoretical conceptual discussion, Social Innovation Research has been intensified and a wide range of activities has been developed to stimulate an interdisciplinary discourse working on its conceptual clarity and theoretical foundations, with the following aims:

- to systematize diverse activities;

- to achieve better theoretical foundation of the term from different theoretical perspectives;

- to establish it as an analytical concept with a clear defined object of study based on interest in knowledge.

In their review of research on Social Innovation, Moulaert et al. (2017) detected a 'growing body of literature focusing on SI as a concept', including 'contributions presenting meta-theoretical, historical and critical perspectives on SI discourse and its influence on contemporary policy and practice' (p. 28).

Stimulated by the strong increase in political and public interest in Social Innovation, the relevant scientific discussion has experienced a significant international upswing in recent years. The efforts to develop a cross-field discourse are increasing, as are the differentiation of the field that has taken place, to give the term a more theoretical foundation as an analytical concept with a clearly defined object of investigation and related epistemological interest (Pol and Ville 2009; Mulgan 2012; Hochgerner 2013; Moulaert et al. 2013; Cajaiba-Santana 2014; Howaldt et al. 2014; Nicholls et al. 2015; Klein et al. 2016; Moulaert and MacCallum 2019). After a long period of almost non-existent or largely neglected conceptual and theoretical debate, contours of an autonomous research field (Whitley 2000; Fagerberg and Verspagen, 2009; Howaldt and Schwarz 2019) are becoming visible, based on a common research object, a shared knowledge base and a working communication structure.

In a collective effort, Social Innovation Research has further established itself as an autonomous research field with an emerging community of researchers (Domanski and Kaletka 2017). The topic is increasingly addressed in journals and edited volumes, leading institutions act as partners in different research projects, network building reinforces an exchange of ideas (e.g. in the European School of Social Innovation, ESSI), with the European Public \& Social Innovation Review (EPSIR), edited by SINNERGIAK, a distinct journal 
in the field being established, and annual (ISIRC) and biannual ESSI conferences ${ }^{1}$ bring together the global research community.

With the scientific debate significantly advancing, Social Innovation has become a contested concept (Ayob et al. 2016); the conceptual and practical ambiguity of Social Innovation Research reflects the openness and diversity of social innovations in practice and can be seen as a strength and sign of the growing maturity.

On the one hand, we find non-normative understandings of Social Innovation, which does not refer to socially desirable or desirable or good as a determining criterion. It is then Social Innovation when certain inventions, ideas and initiatives are imitated, adapted to specific contexts and (thereby) lead to a transformation of social practices in or between specific social groups. This non-normative sociological conception is contrasted with approaches that emphasize the normative element in the sense of a common good orientation as the determining criterion of Social Innovation. In the sense of the latter perspective, social innovations are means to an end, such as the realization of human-wellbeing and sustainable development. Within the context of the EU programmatic framework, social innovations are limited to those innovations that address needs that cannot be satisfied by the market, that improve the quality of life without generating profit, and have the characteristics of public goods (Pol and Ville 2009, p. 15). For the normative conceptualization, in particular the concept of a good or successful life and the capabilities and opportunities for realization, the Capability Approach (CA) is particularly ground-breaking (Sen and Nussbaum 1993; Chiappero-Martinetti and von Jacobi 2015).

Even though sociological analysis emphasizes that social innovations are not good for society per se, but ambivalent in their effects in principle, these two perspectives can be mutually supportive with regard to a deeper theoretical foundation (Howaldt and Schwarz 2017).

\section{New directions and open questions}

However, a theoretically sound concept of Social Innovation is still under construction, with the help of numerous research institutes around the globe, such as the Centre de Recherche sur les Innovations Sociales (CRISES), the Waterloo Institute for Social Innovation and Resilience (WISIR), Stanford University's Center for Social Innovation, The Australian Centre for Social 
Innovation (TACSI), Centre for Social Innovation (ZSI) Vienna, The Social Research Centre at TU Dortmund University, and many more. Even if the field of Social Innovation has reached maturity, we find a lot of conceptual differences in the theoretical fields, not only with regard to the concept and understanding of (social) innovation but also regarding:

- the role of technologies;

- the main actors and drivers;

- the relationship to social change;

- the governance and framework conditions;

- the significance of power and conflict.

Little is known about the relationship to technological and business innovation in processes of transformative change. With SI ecosystems emerging, there is a need for a better understanding of the functions of the different actors and the governance structures. Increased understanding of the processes of SI requires a shift towards studying the interplay between different SI, transcending the limits of single initiatives.

In Europe, a new generation of EU-funded projects has contributed to the theoretical foundation of Social Innovation Research. Among others, these include the TEPSIE project ('Theoretical, Empirical and Policy Foundations for Building Social Innovation in Europe' 2012-2014) which prepared the way for developing tools, methods and policies that would be part of the EU strategy for social innovation, the TRANSIT project (2014-2016) with its aim to develop a transformative social innovation theory of middle range, and the SI-DRIVE project ('Social Innovation - Driving Force of Social Change', 2014-2018) which aimed to integrate theories and methodologies to advance the understanding of Social Innovation and which conducted a global mapping of more than 1000 social innovation initiatives around the globe and established the Atlas of Social Innovation (Howaldt et al. 2018, 2019).

Consequently, an 'evaluation of various FP funded projects [...] reveal[s] that the intellectual capital constructed through the concepts, approaches, policies and practices of SI has matured to an extent whereby we can no longer demote SI to a vague, confusing, half-baked or conflictual concept without theoretical or practice grounds' (Moulaert et al. 2017, p. 43f). 


\section{Three key areas of social innovation research and future challenges}

Against this background, this book gives an in-depth overview of the state of the art in different strands of Social Innovation Research. It outlines a research agenda for Social Innovation while taking into account the broad discussion and the diversity of thematic fields. This collective effort will help to further develop the theoretical foundations of the field and highlight research questions and demands for the upcoming years.

Our goal for this book is to show the range and depth of advances that characterize the field and at the same time move forward by covering new topics, creating new impulses for Social Innovation Research and outline future research pathways. Toward this end, we invited international experts in Social Innovation Research to contribute to this book. By bringing together these leading experts, the Research Agenda provides new insights into current trends of Social Innovation Research as well as possible connections to other schools of thought and research traditions. As diverse as the world of Social Innovation is, the conceptual underpinnings draw upon the experiences of a variety of disciplines contributing to the rich, multi-layered nature of the phenomenon.

The research agenda is structured in three main parts, identifying key areas of research and highlighting future challenges. By differentiating these three parts, the research agenda takes into account the long-term and multi-faceted development of theoretical approaches which help to better understand the topic as a whole. At the same time, it addresses the development of specific thematic focuses and their related communities of research and practice, some of which have come a long way, while some have emerged only in recent years. Some of these actors, infrastructures or methodologies may not always be associated with social innovation at first sight. As previous work has shown, there are parts of the research landscape which - despite their relevance - are sometimes not recognized as such (Domanski and Kaletka 2017).

In the first part, we have brought together contributions that address the history of the concept as well as the theoretical foundations. The focus here lies on the complexity of social innovation processes and the role of social innovations in shaping processes of social change and transformation. This also involves the importance of social innovations in the context of the discussion on sustainable development and their role in managing the digital transformation of our societies. As we know from the long history of Social Innovation 
Research, people play a crucial role in the development and diffusion of social innovations. Through Social Innovation Research, relevant knowledge has been generated regarding the importance of partnerships between stakeholders from different societal sectors to set up social innovations as well as the necessity of linking policies to contribute successfully to social change.

The second part focuses on actors or actor constellations, the importance of capabilities and grassroots innovations. The chapters reflect the state of the art as well as research needs with regard to networks and ecosystems as important preconditions for social innovations and their diffusion in society. Often neglected in this context is the significance of power relations and conflicts, the topic of the concluding chapter of the Research Agenda's second part.

Third, successful social innovations are based on numerous presuppositions and require appropriate infrastructures and methodologies. This includes a new role of public policy and government for creating a suitable framework and support structures as well as scientific progress to be made for the measurement of Social Innovation and their social impact. The chapters in this part give an overview of the state of the art in the related research and point out research desiderata.

\section{Part I: History of the concept and theoretical foundations}

A deep insight into the long history of the concept is given in the chapter by Benoît Godin and Cornelius Schubert. Despite the largely negative connotations that the concept of innovation carried until the twentieth century, a positive notion of innovation as spiritual renewal existed during the English Reformation. This chapter documents this moment, then looks at how innovation came to be seen as progressive social change. The authors emphasize that Social Innovation is mostly used and defined in relation or opposition to technological innovation and that it became much more future-oriented in contrast to the previous state that characterized the positive notion of innovation during the Reformation.

One of the most important results of Social Innovation Research conducted in recent years is a better understanding of the complexity of Social Innovation and its relationship to social change. In their contribution, Howald and Schwarz identify a number of research avenues and outline a research agenda to better understand the relationship between Social Innovation and social change. Starting with a short overview of the state of the art of the conceptualization of social change in Social Innovation Research, they highlight open questions for developing a social-theoretical concept. Although some progress has been 
made in recent years, a widely accepted theoretical model grounded in empirical research is still missing. And thus the chapter concludes with an outline of major research desiderata that could lead to a stronger empirical foundation of the theoretical considerations.

The contribution of Katharine McGowan, Frances Westley, Michele-Lee Moore, Erin Alexiuk, Nino Antadze, Sean Geobey and Ola Tjornbo considers the importance of, and difficulties associated with, studying and fostering transformative social innovation. The chapter explores critical questions related to transformational social innovation, including: the prophetic starting conditions of any innovation; the multi-agent effort over time and scale; the mutual role of the adjacent possibles; paradox and tension of the social innovation process, and the roles of coalition and opposition to transformative change. The contribution advances many conversations about transformative social innovation, a subject that seems to grow in attention as a perceived set of responses to the complex problems around us - new and long-standing. Yet, crucial questions of power, voice and conflict need to be explored as more and more practitioners and academics alike place their hopes in the ambiguous promise of transformative social innovation.

In the next chapter, Jeremy Millard discusses the role of Social Innovation Research in sustainable development. He summarizes the evolution of the concept of Sustainable Development (SD), and examines the current state of the art of Social Innovation support to Sustainable Development across existing research streams. Drawing upon recent desk and case study research, the chapter outlines the future research landscape and proposes three critical future research areas: the climate and environmental crisis, poverty and inequality challenges, and the need for good governance. Overall, the chapter argues that the concepts, methods and tools of Social Innovation are almost uniquely well suited to successfully support both the existing and the climate-focused, post-COVID SD landscape. SI research should concentrate on ensuring its characteristics are designed, tailored and deployed to optimize the achievement of as many sustainable development goals as possible.

Steven Dhondt, Peter R.A. Oeij and Frank D. Pot address the digital transformation of our society and the role of Social Innovation in this mega process. Digital technologies have profound impacts on work settings, in a positive as well as in a negative sense. The authors argue that digital transformation needs to be better understood to see how it can support the active citizen. In becoming socially active in their daily lives, citizens may be impacted by their daily work settings. However, how and to what extent work can influence social participation of citizens needs to be researched. Workplace democracy and 
active work settings - elements of workplace innovation - are important to stimulate citizens to become more active and are therefore relevant for Social Innovation. This chapter develops core ideas for a Social Innovation Research Agenda starting from the future workplace.

\section{Part II: Governance, actors and ecosystems}

With the focus on actors and actor constellations in Social Innovation Research, relevant knowledge has been generated regarding the importance of diverse partnerships between stakeholders from different societal sectors to set up social innovations as well as the necessity of linking policies to contribute successfully to social change.

In his contribution, Rafael Ziegler deals with the importance of the capabilities approach for Social Innovation Research. In his view, innovation belongs to the anatomy of modern societies. Social innovation opens up processes of change and transformation for new actors, networks and ideas. Due to this link, it also faces the challenge of making a structural difference rather than being co-opted. Part of the challenge is the link between social innovation, justice and democracy. The capabilities approach (CA) insists on the role of humans as agents in social processes. Its emphasis on central capabilities as requirements of justice points to the areas where Social Innovation is needed most. It does so with a focus on human diversity in context. Following a review of the literature at the intersection of the capabilities approach and Social Innovation, the chapter concludes with the following research desiderata: a capabilitarian social innovation policy for post-COVID-19, green human development, a more balanced research on social innovation and exnovation, and the development of impact assessment.

Swati Banerjee and Abdul Shaban introduce grassroots innovations which reflect a people-centric approach in Social Innovation that not only helps to integrate epistemic diversities in the context and intersectionality of people's lived experiences, but also has the potential for epistemic inclusion. Their contribution aims at an analytic unpacking of grassroots social innovation with various concepts, perspectives and empirical evidences challenging the dominant notions of both social innovation and grassroots social innovation. The chapter concludes by drafting a critical agenda for future research and practice in Social Innovation by highlighting alternatives that centre-stage people's participation. The focus thus shifts from macro and instrumental perspectives of change to micro and transformative perspectives that re-centre people, their diversities, agency and knowledge emerging from everyday realities of their intersectional lifeworld. 
Carolina Andion and Graziela Dias Alperstadt explore critical contributions in the recent debate on Social Innovation Ecosystems (SIEs). Based on a systematic and conceptual literature review and from the gaps and advances observed in recent scientific articles, this chapter presents perspectives regarding the research agenda on SIEs. The chapter emphasizes the importance of developing less normative frameworks, avoiding standard solutions and universal models to explain Social Innovation and its consequences, and calls for multi-scale and multi-sectoral analyses of SIEs to understand the relationship between Social Innovation and broader processes of social change.

Processes of social innovation and social change are always connected to power constellations and conflict. In their chapter, Simon Teasdale, Michael J. Roy and Lars Hulgård draw upon the concept of strategic action fields to illustrate how different actors collaborate and compete in order to shape a social innovation field. From this perspective, actors seek to influence and change the objectives and power constellations within the field(s), effectively setting out the direction for transformative social change. They achieve this, in part, through discursive strategies aimed at persuading others to their cause. The authors identify three different discourses that are shaping contemporary ideas of what Social Innovation is or ought to be and set out areas of future research that can shed light on social innovation fields as arenas of contestation. They call for a better understanding of how coalitions emerge, and how social innovation fields include and negotiate top-down liberal democratic perspectives with bottom-up communitarian visions.

\section{Part III: Framework conditions and infrastructures}

The following chapters address different aspects of networks and infrastructures as important preconditions for Social Innovation and their diffusion in society.

This part starts with a contribution from Geoff Mulgan, advancing the frontiers of Social Innovation Research and policy, in which he gives an overview of the public debate on Social Innovation in recent years. The chapter suggests a number of possible routes to better answers: addressing the links between Social Innovation and new kinds of social science, including their overlap with social R\&D as an aspect of policy, together with new opportunities of computational social science, the role of labs and social science parks; analysing sectors as industries in order to guide their shaping, and why this scale of analysis, drawing on industrial economics, may be particularly useful for understanding the dynamics of Social Innovation; using data more effectively, and how we may start tracking the growth and evolution of social ideas; and 
last but not least, making sense of policy and designing better policies - what can be learned from the many governments that have over the last decade attempted to support Social Innovation more directly?

Eva Wascher's chapter focuses on collaborative spaces for social innovation. As a social phenomenon, collaborative spaces for social innovations have gained importance throughout at least the last two decades. The chapter investigates the variety of scholarly contributions in the field and tries to grasp some commonalities when talking about impact labs, social innovation labs, public sector labs and GovLabs as well as centres for social innovation. Key characteristics of collaborative spaces for social innovations are discussed along the analytical dimensions of organization, process, space and network. Furthermore, the chapter discusses the likely future importance of innovation labs for social innovation, for instance in innovation systems and as an instrument of collaborative and transformative governance.

Tamami Komatsu Cipriani, Alessandro Deserti and Francesca Rizzo address the importance of design research in and for social innovation. While design tools and methodologies - notably, co-design - have become widespread in innovation activities across sectors, the authors highlight a gap between expert design practice and the use of these tools by non-designers. The chapter explores how design research and its tools can contribute to the growth and development of social innovations and reflects where research is needed to better pursue the final goal of meeting pressing social challenges. Specifically, the chapter focuses on the unique characteristics of social innovation and design, and the need to adapt design tools and develop design practices in the contexts in which they occur and what this implies for both fields.

Klaus Schuch and Nela Šalamon discuss the difficult relation between social innovation and social sciences. In their contribution, the authors scrutinize how deeply academic research, institutionalized by higher education institutions as organizations and by social-scientific disciplines as institutions of thought, is connected to emerging social innovations and Social Innovation Research. They hypothesize that one reason for the alleged academic reluctance towards Social Innovation, in particular within the field of social sciences, is the partial lack of a robust epistemological foundation of Social Innovation Research. They conclude that the lack of institutional and organizational support for Social Innovation Research in the field of higher education negatively affects a stronger academic relationship to the practice field of social innovation and, as a consequence, to transformative research approaches. 
The book ends with the important quest for concepts to appropriately measure Social Innovation. In their chapter, Judith Terstriep, Gorgi Krlev, Georg Mildenberger, Simone Strambach, Jan-Frederik Thurmann and Laura Wloka define social innovation as a transformational process affecting social practices by providing more social value to society. In their chapter, the authors review rare previous research measuring social innovation, develop an integrated measurement model that offers advanced research in this area, and demonstrate how the model has been empirically tested. They discuss how research on social innovation measurement can improve the understanding of the complexities of Social Innovation, and the shaping of emergent social practices.

\section{Conclusion and outlook}

The chapters collected in this book demonstrate that an intensive discussion has unfolded in central areas of Social Innovation Research in recent years, which has contributed to a theoretical foundation of the research field and to the development of a common knowledge base. The goal of this book is to showcase the range and depth of advances that characterize Social Innovation Research and at the same time point out research desiderata and stimulate future research.

Topics such as the relationship between Social Innovation and social change, governance, actors and ecosystems, framework conditions and infrastructures are addressed from different perspectives and contribute to building a solid and robust foundation of Social Innovation Research.

While the chapters of the book reflect the progress made, they particularly highlight unresolved issues and gaps and indicate directions for further exploration.

Apart from the progress made, we also find some conceptual differences in the theoretical fields - not only with regard to the concept and understanding of innovation, but also concerning:

- the mechanisms of Social Change and societal transformation;

- the understanding of Social Innovation ecosystems and their role in processes of Social Innovation;

- the role of policy in promoting and enabling Social Innovation. 
Building on the results of the presented status quo and recent progress in the research fields, future research should especially prioritize the following major topics:

- The regional, cultural and social context of Social Innovation. This also asks for a better understanding of the conditions for implementing Social Innovation, and of the emergence (or establishment) of favourable Social Innovation ecosystems.

- Further insights into the possible and favourable outcomes and impacts of new practices, ranging from improving the living and working conditions of vulnerable or disadvantaged social groups to triggering, enhancing or driving favourable social change and/or limiting/compensating the impact of less beneficial social change. This includes the development of indicators (such as social Key Performance Indicators (KPIs) or 'Societal Relevance Levels' compared with the 'Technological Readiness Levels') that are suitable for a better social and economic impact as well as added social value measurement.

- The relationship to technological and business innovation in processes of transformative change (e.g. the 'socio-digital transformation', the socio-ecological transition, etc.).

- The long-term impacts on existing practices and institutions have hardly been examined so far. A specific focus should be laid on the ambivalence of social innovations. The implementation of innovation and new technologies goes along with the displacement of previous ones. While innovation generates winners, it also generates losers at the same time (Kogan et al. 2013). In fact, this ambivalence was acknowledged as early as when Schumpeter introduced the process of 'creative destruction', even though the vast majority of studies including the analysed cases within the SI-DRIVE project clearly focus on the successful and positive effects of innovation processes.

The debate on Social Innovation is receiving new impulses from research on sustainable development, which can be interpreted as a further development of established transformation research. Social Innovations that unleash new values and practices take a key position here (Howaldt and Schwarz 2016). With regard to the mobilization of social transformation processes and related recent development theory perspectives, for example, Frances Westley and colleagues (Moore et al. 2012) attempt to make the concept of resilience useful for Social Innovation Research.

Another approach is described by scholars from the Dutch Research Institute for Transitions (DRIFT), which is renowned in the field of transition research. 
The starting point of the Transit Project was the question of the transformative potential of Social Innovation (Avelino et al. 2014; Wittmayer et al. 2019; Pel et al. 2020). A heuristic was developed that aims to avoid determinant factors and takes into account 'that societal transformation is shaped and produced by particular patterns of interaction between social innovation, system innovation, game-changers and narratives of change. Individual actors, initiatives and networks, are empowered (or disempowered) to contribute to this process through different forms of governance, social learning, resourcing, and monitoring' (Avelino et al. 2014, p. 5).

An integration of this model into a social-theoretically grounded perspective on social change - understood as the transformation of social practices - is seen as necessary. Therefore, a social theoretical further development is seen as imperative (Avelino et al. 2014). In this context, practice theories take transitions in practices as the actual object of study. By focusing on social practices, it is possible to understand the emergence of social conditions and transformative change can be analysed and understood (Howaldt and Schwarz 2016). The challenge of advancing sustainable lifestyles and economic practices refers, at its core, to the theme of reconfiguring of social practices (Shove et al. 2012, p. 137).

The development of a theoretically sound concept of Social Innovation is a precondition to elaborate an integrated theory of innovation which considers social, business, public sector and technological innovation under one common umbrella concept of innovation. It is also a precondition for strategic Social Innovation policy as part of comprehensive Research, Technology, Development and Innovation (RTDI) policies. An extended notion and generic understanding of 'innovation', comprising the classic concept of innovation, considering also the social impact of business innovations plus the particularities of Social Innovation, may unleash a new complex of policies relevant for societal, economic and technology evolution. It could be termed or encompass the following components respectively: Research, Technology in Society Development and Innovation (RTSDI) policy. The great challenge for contemporary innovation research lies in analysing the potential of Social Innovation in the creation of new social practices that enhance an inclusive, equitable, democratic, participative, and above all socially anchored future. This will allow people to live richer, more fulfilled and prosperous lives.

Last but not least we would like to mention that this book is part of a much broader project: to create a solid and robust knowledge base for a growing global and diverse Social Innovation Community (Howaldt et al. 2018, 2019) working on the creation of a supportive framework and a social innovation-friendly 
environment paving the way to create a world of new practices. In this spirit, this book is also a contribution to underpin these network activities by providing a theoretical foundation and an agenda for future research.

\section{Notes}

1. The International Social Innovation Research Conference (ISIRC) is the world's leading interdisciplinary social innovation research conference (https://www .isirc2021milano.com/?avia_forced_reroute=1\#about). The European School of Social Innovation (ESSI), together with its partner organizations, is conducting a biannual series of international conferences on Social Innovation. This series is designed to strengthen international research networks on Social Innovation and to develop a common research programme (e.g. as outlined for the first time in the 'Vienna declaration on social innovation' 2011 and the 'Lisbon Declaration: Social Innovation as a Path to a Sustainable, Resilient, and Inclusive Europe' 2018) (https://www.essi-net.eu/?p=2177).

\section{References}

Avelino, F., J. Wittmayer, A. Haxeltine, R. Kemp, T. O’Riordan, P. Weaver, D. Loorbach et al. (2014), 'Game-changers and transformative social innovation. The case of the economic crisis and the new economy', TRANSIT Working Paper, accessed 17 March 2021 at http://www.transitsocialinnovation.eu/content/original/TRANSIT \%20outputs/91\%20Gamechangers_TSI_Avelino_etal_TRANSIT_workingpaper 2014.pdf.

Ayob, N., S. Teasdale and K. Fagan (2016), 'How social innovation "came to be": Tracing the evolution of a contested concept', Journal of Social Policy, 45(4), pp. 635-53.

Cajaiba-Santana, G. (2014), 'Social Innovation: Moving the field forward. A conceptual framework', Technological Forecasting and Social Change, 82, pp. 42-51.

Chiappero-Martinetti, E. and N. von Jacobi (2015), 'How can Sen's “Capabilities Approach" contribute to understanding the role for social innovations for the marginalized?', CRESSI Working Papers, 3/2015, D1.1., accessed 17 March 2021 at https://core.ac.uk/download/pdf/288289279.pdf.

Choi, N. and S. Majumdar (2015), 'Social innovation: Towards a conceptualisation', in S. Majumdar, S. Guha and N. Marakkath (eds), Technology and Innovation for Social Change, New Delhi: Springer, pp. 7-34.

De Bruin, A. and S. Teasdale (eds) (2019), A Research Agenda for Social Entrepreneurship, Cheltenham, UK and Northampton, MA, USA: Edward Elgar Publishing.

Domanski, D. and C. Kaletka (eds) (2017), Exploring the Research Landscape of Social Innovation - a deliverable of the project Social Innovation Community (SIC), Dortmund: Sozialforschungsstelle.

Fagerberg, J. and B. Verspagen (2009), 'Innovation studies - The emerging structure of a new scientific field', Research Policy, 38, pp. 218-33. 
Franz, H.-W., J. Hochgerner and J. Howaldt (2012), Challenge Social Innovation: Potentials for Business, Social Entrepreneurship, Welfare and Civil Society, Berlin, Germany and New York, NY, USA: Springer.

Godin, B. (2012), 'Social Innovation: Utopias of innovation from c.1830 to the present. Project on the intellectual history of innovation', Working Paper No. 11, Montreal, Quebec.

Hochgerner, J. (2013), 'Social innovation and the advancement of the general concept of innovation', in C. Ruiz Viñals and C. Parra Rodríguez (eds), Social Innovation: New Forms of Organisation in Knowledge-based Societies, Abingdon: Routledge, pp. 12-28.

Howaldt, J. and M. Schwarz (2010), Social innovation: Concepts, Research Fields and International Trends, Dortmund: TU Dortmund, Sozialforschungsstelle, accessed 17 March 2021 at http://www.sfs.tu-dortmund.de/cms/Medienpool/small _publications/Doc_1289_IMO_Trendstudie_Howaldt_Schwarz_englische_Version .pdf.

Howaldt, J. and M. Schwarz (2016), 'Social innovation and its relationship to social change. Verifying existing social theories in reference to social innovation and its relationship to social change', SI-Drive Report D 1.3., accessed 22 March 2021 at https://si-drive.archiv.zsi.at/wp-content/uploads/2017/12/SI-DRIVE-D1-3-Social -Change-final-260416-2.pdf.

Howaldt, J. and M. Schwarz (2017), 'Social innovation and human development: How the capabilities approach and social innovation theory mutually support each other', Journal of Human Development and Capabilities, 18(2), pp. 163-80.

Howaldt J. and M. Schwarz (2019), 'Soziale Innovation', in B. Blättel-Mink, I. Schulz-Schaeffer and A. Windeler (eds), Handbuch Innovationsforschung, Wiesbaden: Springer VS.

Howaldt, J., A. Butzin, D. Domanski and C. Kaletka (2014), 'Theoretical approaches to social innovation: A critical literature review', Social Innovation: Driving Force of Social Change (SI-DRIVE), Dortmund: Sozialforschungsstelle, accessed 17 March 2021 at http://www.si-drive.eu/wp-content/uploads/2014/11/D1_1-Critical -Literature-Review_final.pdf.

Howaldt, J., C. Kaletka, A. Schröder and M. Zirngiebl (2018), Atlas of Social Innovation - New Practices for a Better Future. Sozialforschungsstelle, TU Dortmund University: Dortmund.

Howaldt, J., C. Kaletka, A. Schröder and M. Zirngiebl (2019), Atlas of Social Innovation - 2nd Volume: A World of New Practices, Munich: Oekom Verlag.

Klein, J.-L., C. Jetté, A. Camus, C. Champagne and M. Roy (2016), La Transformation Sociale par l'innovation Sociale, Quebec: Presses de l'Université du Quebec.

Kogan, L., D. Papanikolaou and N. Stoffmann (2013), 'Winners and losers: Creative destruction and the stock market', NBER Working Paper No. w18671, accessed 17 March at https://ssrn.com/abstract=2196736.

Moore, M.-L., F. Westley, O. Tjornbo and C. Holroyd (2012), 'The loop, the lens, and the lesson: Using resilience theory to examine public policy and social innovation', in A. Nicholls and A. Murdock (eds), Social Innovation: Blurring Boundaries to Reconfigure Markets, New York: Palgrave Macmillan, pp. 114-36.

Moulaert, F. and D. MacCallum (2019), Advanced Introduction to Social Innovation, Cheltenham, UK and Northampton, MA, USA: Edward Elgar Publishing.

Moulaert, F., A. Mehmood, D. MacCallum and B. Leubolt (2017), Social Innovation as a Trigger for Transformations: The Role of Research, Brussels: European Commission. 
Moulaert, F., D. MacCallum, A. Mehmood and A. Hamdouch (2013), The International Handbook on Social Innovation. Collective Action, Social Learning and Transdisciplinary Research, Cheltenham, UK and Northampton, MA, USA: Edward Elgar Publishing.

Moulaert, F., F. Martinelli, E. Swyngedouw and S. González (2005), 'Towards alternative model(s) of local innovation', Urban Studies, 42(11), pp. 1969-90.

Mulgan, G. (2012), 'Social innovation theories: Can theory catch up with practice?' in H.-W. Franz, J. Hochgerner and J. Howaldt (eds), Challenge Social Innovation: Potentials for Business, Social Entrepreneurship, Welfare and Civil Society, Berlin, Germany and New York, NY, USA: Springer, pp. 19-42.

Mulgan, G. (2019), Social Innovation: How Societies Find the Power to Change, Bristol: Policy Press.

Nicholls, A. and R. Ziegler (eds) (2019), Creating Economic Space for Social Innovation, Oxford: Oxford University Press.

Nicholls, A., J. Simon and M. Gabriel (2015), New Frontiers in Social Innovation Research, New York: Palgrave.

Pel, B., A. Haxeltine, F. Avelino, A. Dumitru, R. Kemp, T. Bauler, I. Kunze et al. (2020), 'Towards a theory of transformative social innovation: A relational framework and 12 propositions', Research Policy, 49(8), 104080.

Pol, E. and S. Ville (2009), 'Social innovation: Buzz word or enduring term?' The Journal of Socio-Economics, 38, pp. 878-85.

Pue, K., C. Vandergeest and D. Breznitz (2016), 'Toward a theory of social innovation', Innovation policy lab white paper, 2016-01, Munk School of Global Affairs, Toronto: University of Toronto.

Rüede, D. and K. Lurtz (2012), 'Mapping the various meanings of social innovation: Towards a differentiated understanding of an emerging concept', EBS Business School Research Paper, No 12-03, accessed 17 March 2021 at http://papers.ssrn.com/ sol3/papers.cfm?abstract_id=2091039.

Sen, A. and M. Nussbaum (1993), The Quality of Life, Oxford: Clarendon Press.

Shove, E., M. Pantzar and M. Watson (2012), The Dynamics of Social Practice: Everyday Life and How it Changes, Los Angeles, CA: SAGE.

Whitley, R. (2000), The Intellectual and Social Organization of the Sciences, Oxford: Oxford University Press.

Wittmayer, J.M., J. Backhaus, F. Avelino, B. Pel, T. Strasser, I. Kunze and L. Zuijderwijk (2019), 'Narratives of change: How social innovation initiatives construct societal transformation', Futures, 112, 102433. 
Jürgen Howaldt, Christoph Kaletka, and Antonius Schröder - 9781789909357 Downloaded from PubFactory at 04/26/2023 12:23:44PM 